\title{
СИСТЕМНЫЙ ИНСТРУМЕНТАРИЙ ОРГАНИЗАЦИОННО-ПРАВОВЫХ ОСНОВ В СФЕРЕ ОБОРОННО-ПРОМЫШЛЕННОГО КОМПЛЕКСА: ФОРМИРОВАНИЕ И СОВЕРШЕНСТВОВАНИЕ
}

\author{
(c) 2021 Сингилевич Дмитрий Александрович \\ кандидат военных наук, доцент, полковник запаса \\ Москва \\ E-mail: dsingilevich@yandex.ru \\ (C) 2021 Шурукова Елена Евгеньевна \\ аспирант \\ ИПУ РАН, Россия, Москва \\ E-mail: agor80@yandex.ru
}

Руководитель секции правовых проблем обороны государства - заместитель руководителя Экспертного совета Комитета Государственной Думы Российской Федерации по обороне, Россия,

В статье рассматривается процесс формирования системы основных организационных и правовых инструментов в оборонно-промышленном комплексе, и определяются направления их дальнейшего совершенствования.

Ключевые слова: организационно-правовые основы, формы и методы регулирования, оптимизация организационных структур, маркетинговая деятельность, правовое регулирование инвестиционной деятельности, система инструментов.

Стремительное изменение военнополитической и экономической обстановки в мире в сторону глобализации через конфликтизацию с последующей изоляцией российской экономики обусловливает необходимость скорейшего развития наиболее важных наукоемких и высокотехнологичных отраслей народного хозяйства, к которым безусловно относятся все направления деятельности российского обороннопромышленного комплекса [1,4].

Разразившийся в марте-апреле 2021 года глобальный кризис на рынке микросхем, вызванный гигантским дефицитом полупроводников, с которым столкнулась мировая промышленность лишний раз подтверждает это [2]. Внезапный дефицит ключевых компонентов, от которых зависит функционирование всех современных электронных устройств, от ноутбуков до мобильных телефонов, независимо от причин может серьезно затронуть Россию, доля которой на мировом рынке потребителей электроники составляет около 2\%. Драматичность ситуации заключается в том, что российский рынок электроники на 95\% состоит из комплектующих из-за рубежа, поэтому их глобальная нехватка коснется как производителей, так и потребителей. Причиной прекращения поставок в Россию микросхем и полупроводников стали как нало- женные санкции, так и пандемия, в результате чего отечественный автопром стал испытывать потребность в чипах для систем «Эра-ГЛОНАСС», тахографов, панелей управления приборами, блоков управления двигателем, кузовной электроникой и других необходимых систем. В складывающейся ситуации эксперты прогнозируют сокращения объемов производства, как следствие появления дефицита новых автомобилей и рост цен на них, в связи с тем, что без этих компонентов, особенно «Эра-ГЛОНАСС», российские автомобили в том числе и для Вооруженных Сил, не могут быть выпущены.

Российские производители вычислительной техники и радиоэлектроники не могут пока отказаться от некоторых зарубежных решений и компонентов, а если и используют ряд отечественных решений, то для очень узких задач [3, 9]. При этом в России есть возможности по наращиванию собственного производства микросхем и полупроводников, но для этого необходимо выделять производителям государственные субсидии и обеспечивать их большими заказами.

Глобальный кризис на рынке микросхем, набирающий обороты на момент написания статьи подтверждает, что развитие отраслей ОПК потребует существенных инвестиций в них как со стороны государства, так и со стороны част- 
ных инвесторов.

Инвестирование в ОПК требует формирования благоприятного инвестиционного климата, что зависит от качества и эффективности организационно-правового обеспечения в данной сфере $[8,11]$.

В свою очередь качество и эффективность организационно-правового обеспечения в сфере ОПК зависит от того какие, в каком сочетании и в какой последовательности используются организационные, правовые и маркетинговые инструменты $[5,6]$.

В целях обеспечения качественных организационно-правовых основ формирования инвестиционного климата представляется обоснованным из всей совокупности организационно-правовых инструментов, рассматривая их как составную часть системного инструментария государственного регулирования экономики в целом и инвестиционной деятельности в частности, выбрать наиболее необходимые и перспективные в сфере инвестирования и систематизировать их $[7,10,12,15]$.

Согласно Федеральному закону «Об инвестиционной деятельности в Российской Федерации, осуществляемой в форме капитальных вложений» [13] федеральные органы государственной власти для регулирования инвестиционной деятельности, осуществляемой в форме капитальных вложений, используют в том числе следующие формы и методы:

- установление субъектам инвестиционной деятельности специальных налоговых режимов, не носящих индивидуального характера [8];

- защита интересов инвесторов;

- расширения использования средств населения и иных внебюджетных источников финансирования жилищного строительства и строительства объектов социально-культурного назначения;

- создания и развития сети информационноаналитических центров, осуществляющих регулярное проведение рейтингов и публикацию рейтинговых оценок субъектов инвестиционной деятельности [14];

- принятия мер по прекращению и предупреждению нарушений антимонопольного законодательства Российской Федерации;

- развития финансового лизинга в Российской Федерации [6, 7];

- создания возможностей формирования субъектами инвестиционной деятельности соб- ственных инвестиционных фондов;

- выработки и реализации государственной политики и нормативно-правового регулирования в сфере нормирования и ценообразования при проектировании и строительстве;

- разработки, утверждения и финансирования инвестиционных проектов, осуществляемых Российской Федерацией совместно с иностранными государствами, а также инвестиционных проектов, финансируемых за счет средств федерального бюджета;

- ежегодного формирования федеральной адресной инвестиционной программы на очередной финансовый год и плановый период, утверждаемой соответствующим государственным органом, и ее реализации в порядке, установленном Правительством Российской Федерации;

- проведения экспертизы инвестиционных проектов в соответствии с законодательством Российской Федерации;

- выпуска облигационных займов, гарантированных целевых займов.

Названные формы и методы государственного регулирования экономики распределяются по следующим группам инструментов:

- организационные (административные) инструменты;

- правовые инструменты;

- финансовая (налоговая) система;

- кредитно-денежная система;

- государственная собственность;

- государственный заказ.

В данном перечне в целом наличествуют инструменты, необходимые для организационноправового обеспечения инвестиционной деятельности, как составной части государственного регулирования. Однако в рамках регулирования организационно-правовых основ формирования инвестиционного климата наряду с организационными и правовыми инструментами необходимо учитывать и комплекс инструментов маркетинга, которые обеспечивают исследование целевой аудитории (рынка), формирование положительного имиджа как ОПК в целом, так и предприятий по отдельности и его продвижение на внутреннем и внешнем рынках.

Организационные инструменты, обеспечивающие реализацию функций планирования, организации, контроля включают:

- структурные (организационно-штатные) создание реорганизация и реструктуризация 
предприятий, отраслей, кластеров ОПК;

- управленческие - планирование, прогнозирование, мониторинг и контроль, участие в управлении предприятиями ОПК;

- коммуникационные - информационное обеспечение и консалтинг;

- разрешительные - установление требований к сертификации и качеству продукции, лицензирование операций по экспорту и импорту продукции;

- ограничительные - установление государством на определенный период количественных или стоимостных ограничений объема экспорта и импорта товаров (работ, услуг) определенной номенклатуры в натуральном или стоимостном выражении) - квотирование;

- фискальные - контроль над ценами, контроль доходов, контроль валютного курса, антимонопольное регулирование и наложение санкций - ограничений или запретов на производство продукции, работ, услуг.

Таким образом применение организационных инструментов обеспечивает функционирование предприятий ОПК в соответствии с предназначением, что способствует формированию инвестиционного климата и оказывает благоприятное воздействие на инвесторов.

Маркетинговые инструменты, представляют собой комплекс мер или действий, направленных на обеспечение формирования благоприятного инвестиционного климата посредством влияния на приобретателей продукции ОПК и макросреду в целом. Широкий спектр инструментов маркетинга, тесно взаимосвязанных друг с другом, включает:

- маркетинговые исследования, направленные на изучение рынка вооружений, военной и специальной техники и потенциальных покупателей (целевой аудитории), возможных театров военных действий, предполагаемых противников, уровня подготовки конечных пользователей;

- товарную политику, проводимую с учетом результатов маркетинговых исследований - кому и что предлагать, для кого и что производить, особенности экспортных вариантов поставляемых образцов вооружения и военной техники, совместное производство, продажа технологий и организация производства в стране заказчика;

- ценовую политику (цена) - союзникам и друзьям с максимальной программой скидок, многолетним партнерам с максимальными преференциями, предложение кредитов под закупки $\mathrm{BB}(\mathrm{C}) \mathrm{T}$;

- сбытовую политику (каналы сбыта) - opганизация представительств в странах крупнейших заказчиков, подготовка и обучение персонала параллельно изготовлению заказа, доставка заказа к заказчику;

- политика продвижения (коммуникаций) организация интегрированных маркетинговых кампаний (рекламные и PR, выставки и ярмарки), демонстрация успешного применения на полигонах и в реальных условиях;

- послепродажное сервисное обслуживание - организация сопровождения закупленного BB(C)Т в течении всего периода эксплуатации, в том числе ремонт, техническое обслуживание, доработки и усовершенствование и др.

В целом инструменты маркетинга формируют систему маркетинга предприятия (отрасли, кластера), от эффективности которой во многом и зависит успех её деятельности, прочность связей между клиентом и предприятием и самое важное - инвестиционная привлекательность.

Правовые инструменты представляют собой систему устанавливаемых норм и правил, состоящую в разработке законов, устанавливающих нормы инвестиционной деятельности, защиту прав инвесторов и интересов государства, равноправие участников инвестиционной деятельности.

К инструментам правового регулирования предлагается относить:

- нормотворчество - разработку, принятие и издание нормативных правовых (законодательных) и индивидуальных (подзаконных) актов;

- договорную деятельность - заключение договоров (инвестиционных, кредитных соглашений);

- инвестиционные программы - разработку, принятие и реализацию государственных (региональных) инвестиционных программ;

- защиту прав и интересов - систему реализации и соблюдения инвестиционного законодательства, защиты прав и законных интересов участников инвестиционной деятельности.

Таким образом совокупность форм, методов, комплексов мер направленных на организационно-правовое обеспечение инвестиционной деятельности в сфере ОПК в условиях глобальной цифровизации в целом и на формирование 


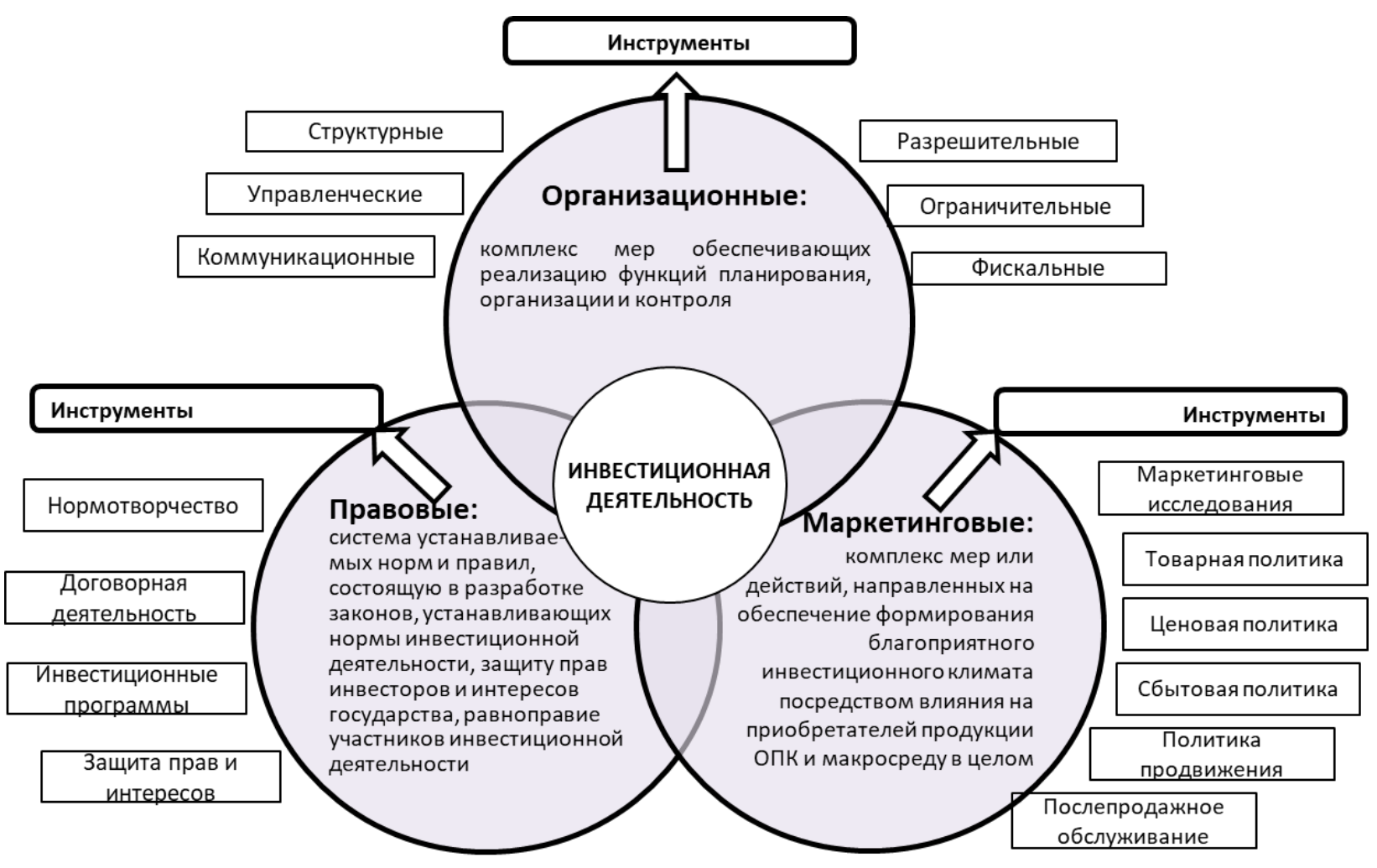

Рис. 1. Инструментарий организационно-правовых основ обеспечения инвестиционной деятельности

инвестиционного климата в данной отрасли в частности, после проведенного изучения, упорядочивания и систематизации представляют собой систему инструментов позволяющих в рамках организационно-правовых основ регулировать инвестирование в предприятия ОПК с максимальной эффективностью.

\section{Библиографический список}

1. Бесполезное оружие приносит Америке гигантские убытки [Электронный ресурс]. - Режим доступа: https:// vz.ru/world/2021/3/28/ 1091060.html/ (дата обращения 28.03.2021).

2. Вклады населения в банках превысили 30 трлн. рублей. Ведомости 29.01.2020. [Электронный ресурс].- Режим доступа: /https://www.vedomosti.ru/personal_finance/ articles/2020/01/29/821756-vkladi-naseleniya-30/ (дата обращения 28.03.2021).

3. Выступление Президента Российской Федерации В.В.Путина на подписании Генеральное соглашение между объединениями профсоюзов, работодателей и Правительством на 2021-2023 годы. [Электронный pecypc]. - Режим доступа: http://www.kremlin.ru/events/president/news/65257/ (дата обращения 28.03.2021).

4. Горохова А., Секерин В., Нижегородиев Р. Экономический потенциал и конкурентоспособность региона как источники экономического роста // РИСК: Ресурсы, Информация, Снабжение, Конкуренция. 2012. № 2. С. 206-208

5. Горохова А. Е. Совершенствование процесса стратегического управления промышленным предприятием // МИР (Модернизация. Инновации. Развитие). 2015. Т. 6. № 2-1 (22). С. 102-107

6. Ефремов А.А. Лизинговые отношения в формировании цепей поставок // Проблемы современной экономики. 2011. № 1 (37). С. 145-148

7. Ефремов А.А. Логистическая стратегия развития сетевых структур лизинга // Известия СанктПетербургского университета экономики и финансов. 2012. № 1 (73). С. 68-74

8. Мальщева Ю. Н. Инвестиции: конспект лекций.- Эксмо; Москва; 2008-170 с. 
9. Незнанова Л.А. Диагностика сформированности правовой компетентности будущего социального работника/ Личностное и профессиональное развитие будущего специалиста. Материалы ХІІ Международной научно-практической конференции Internet-конференции. Министерство образования и науки Российской Федерации / Тамбовский государственный университет имени Г. Р.Державина - 2016., С.385-391.

10. Пыткин А.Н., ХисамоваА.И. Организационные и экономические инструменты управления предприятиями энергетики в конкурентной среде/ Российское предпринимательство. - 2013. - № 15 (237). - С.109-122.

11. Секерин В.Д. Горохова А.Е. Инновационная среда как фактор эффективности коммерциализации инноваций // Известия Московского государственного технического университета МАМИ. 2014. Т. 5. № 2 (20). С. 39-43

12. Секерин В.Д., Кузнецова О.С. Разработка стратегии управления инновационным проектом // Вестник Московской государственной академии делового администрирования. Серия: Экономика. 2013. № 1 (20). С. 129-134

13. Федеральный закон «Об инвестиционной деятельности в Российской Федерации, осуществляемой в форме капитальных вложений» от 25.02.1999 № 39-ФЗ. [Электронный ресурс].- Режим доступа: http://www. consultant.ru/document/cons_doc_LAW_22142//(дата обращения 26.04.2021).

14. Щербаков В.В., Букринская Э. М., Гвилия Н. А., Дмитриев А. В., Ефремов А. А., Килль М. Ю., Павлов М. Ю., Рудковский И.Ф., СмирноваЕ.А. Логистика и управление цепями поставок. Учебник / Москва, 2019. Сер. 68 Профессиональное образование (1-е изд.)

15. Sekerin V.D., Dudin M.N., SkubriyE. V., GorokhovaA.E., Komlatsky G. V. Economic and mathematical modeling of enterprises' demand for labor power in the era of digital economy// International Journal of Engineering and Technology (UAE). 2018. T. 7. № 4.38. C. 456-458 